\title{
Giant Submandibular Duct Calculus: A Case Report
}

\section{Chu Mustapha*}

Department of Cardiology, Algiers, Algeria

\begin{abstract}
Salivary gland stones (Sialothiasis) most commonly occur in the Submandibular duct. This report describes the case of a patient who had an unusual large submandibular gland sialolith (calculus) that was completely obstructing the submandibular gland duct and the use of the computed tomography (CT) as a diagnostic aid and a surgical guide. Patients with sialolithiasis require definitive surgical treatment in most cases, which results in an excellent prognosis.
\end{abstract}

Keywords: Sialolith; Sialolothiasis; Submandibular duct; Calculi; Giant salivary gland stones

\section{Introduction}

The great majority of salivary calculi $(80 \%)$ occur in the submandibular gland and in the duct [1]. Commonly, Sialoliths measure from $1 \mathrm{~mm}$ to less than $1 \mathrm{~cm}$. Giant salivary gland stones (GSGS) are those stones measuring over $1.5 \mathrm{~cm}$ and have been rarely reported in the medical literature [2]. GSGS measuring over $3 \mathrm{~cm}$ are extremely rare, with only scanty reported cases [3].

\section{Case Report}

45 years male patient came with chief complaints of pain in left submandibular region since 4 months. Pain was dull in nature and radiating to the left ear. Pain was aggravated with intake of food. Patient also complained of hard swelling in left sublingual region near the floor of mouth. There were no complaints of recurrent submandibular gland infection in the past. Examination revealed a $3 \times 1 \mathrm{~cm}$ swelling over the floor of mouth on left side. Swelling was hard in consistency, not adherent to the mandible or surrounding structures. Overlying mucosa was free and not inflamed. On bimanual palpation left submandibular gland was not palpable. Cervical lymph nodes were not palpable.

CT examination revealed a single radiopaque density measuring approximately $3 \times 0.4 \mathrm{~cm}$ in left submandibular duct (Figure 1 ). Other lab investigations were within normal limits. The patient was posted for left submandibular duct calculus extraction under GA. Intra-operatively two calculi were removed by taking an incision over left submandibular duct and by marsupialization of the opened duct (Figure 2). Two calculi largest measuring $2.5 \mathrm{~cm}$ and other of $0.7 \mathrm{~cm}$ were removed (Figure 3). Post operatively patient made an uneventful recovery.

\section{Discussion}

The great majority of salivary calculi $(80 \%)$ occur in the submandibular gland and in the duct. Ten percent occur in the parotid and the remaining $10 \%$ in the sublingual gland and the minor salivary glands [1]. Flow of saliva against gravity, its more alkaline $\mathrm{p}^{\mathrm{H}}$, and the high mucin and calcium content could explain the preferential stone formation in the submandibular gland [4]. The exact etiology and pathogenesis are still unknown. There is a slight predilection for occurrence in men, usually above the age of 40 years [5]. Patients present with pain, discomfort, and swelling before or during meals. Recurrent submandibular swelling is often mentioned. Bimanual massage of the affected gland and the excretory duct should be carried out, observing the flow and the clearness of the saliva. The calculus can often be located in the excretory duct, often quite anterior. This characteristically causes pain.

Submandibular gland calculi have been reported to be radiopaque

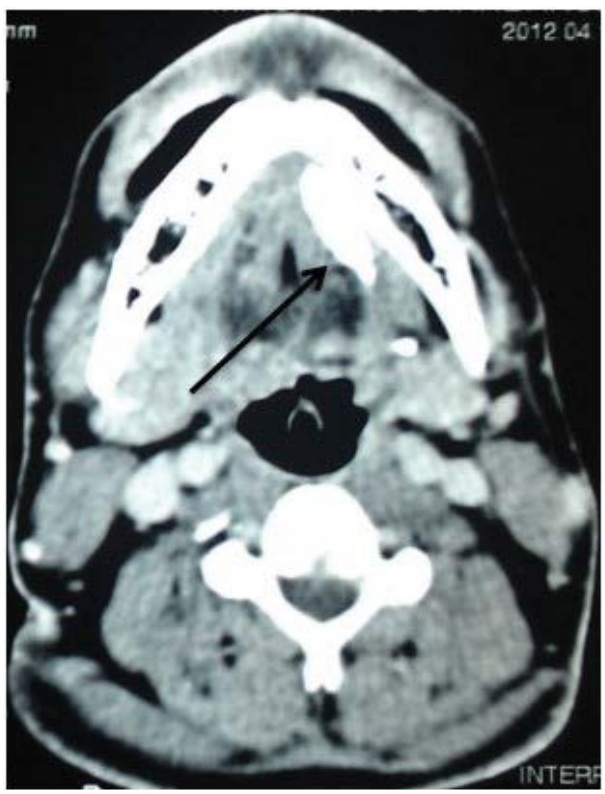

Figure 1: CT showing $3 \times 0.4 \mathrm{~cm}$ calculus in left submandibular duct.

in $80 \%$ to $94.7 \%$ of cases $[7,8]$. Ultrasonography is widely reported as being very helpful in detecting salivary stones. As many as $90 \%$ of all stones larger than $2 \mathrm{~mm}$ can be detected as echo dense spots on ultrasonography [9]. Computed tomography (CT) is also highly diagnostic [8]. When located in the submandibular gland itself a panoramic radiograph may be helpful. In small and radiolucent calculi radiographic findings may be negative and sialography can be the examination of choice, although displacement of the calculus toward the gland cannot always be avoided. Although large sialoliths have been reported both in salivary glands and in salivary ducts, stones larger than $3 \mathrm{~cm}$ are rare. The giant sialolith in this patient was completely encased in the duct of the submandibular gland.

*Corresponding author: Chu Mustapha, Department of Cardiology, Algiers, Algeria Tel: 0021355552845; E-mail: aitmokhtar1@yahoo.fr

Received October 26, 2015; Accepted November 20, 2015; Published November 28 2015

Citation: Mustapha C (2015) Giant Submandibular Duct Calculus: A Case Report. Surgery Curr Res 6: 253. doi:10.4172/2161-1076.1000253

Copyright: ( 2015 Mustapha C. This is an open-access article distributed under the terms of the Creative Commons Attribution License, which permits unrestricted use, distribution, and reproduction in any medium, provided the original author and source are credited. 


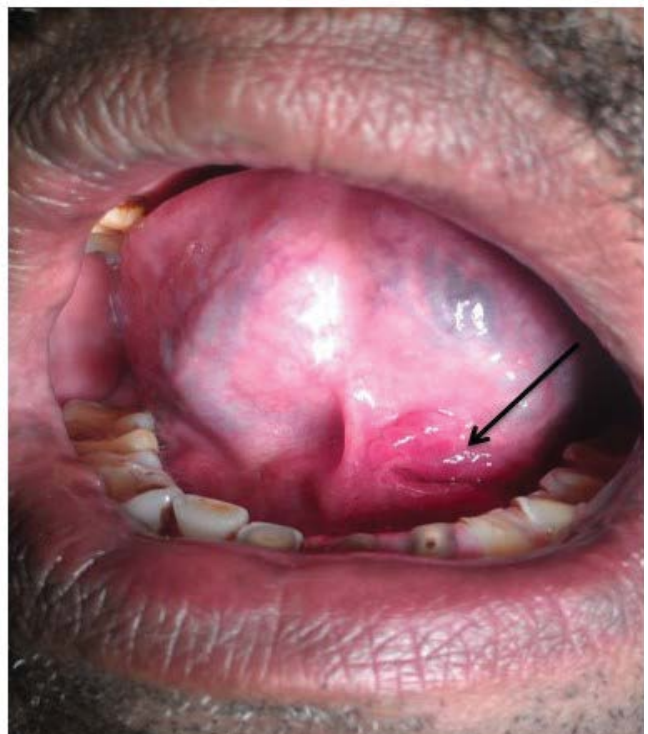

Figure 2: Marsupilized left sub-mandibular salivary duct - 6th post-op day.

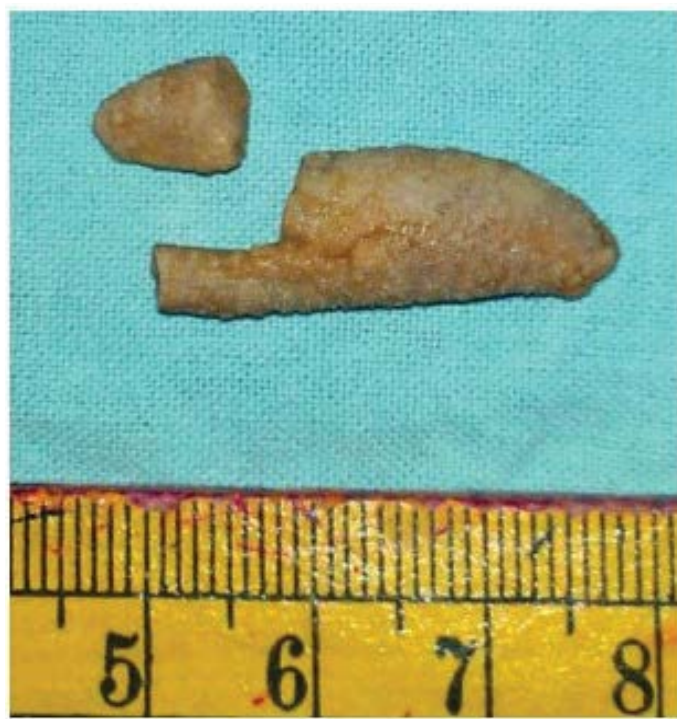

Figure 3: Extracted calculi from the sub-mandibular salivary gland duct.
Sialoliths are ovoid or round, smooth or rough with a yellowish colour. They consist of calcium phosphate with small accounts of hydroxyapatite, magnesium, potassium and ammonia [7].

Submandibular stones are typically removed surgically via either an intraoral or an external approach [10]. Surgical removal of the calculi is performed when located in the excretory duct near the opening. If the calculi are located in the gland itself, fragmentation can be performed by extracorporal or endoscopic laser lithotripsy [11]. In a non-functioning gland surgical removal would be indicated to avoid recurrent disease. In many cases removal of the gland may be the first choice of treatment. The future holds great promise due to the developments of nonsurgical, non-invasive techniques such as shock wave lithotripsy, basket retrieval, and endoscopic laser lithotripsy [11].

\section{References}

1. Seifert G, Mann W, Kastenbauer E, Sialolithiasis (1992) In: Naumann HH, Helms J, Herberhold C, Kastenbauer E eds. Oto-Rhino-Laryngology, 2 [in German]. Stuttgart, Germany: Georg Thieme Verlag 729-32.

2. Soares EC, Costa FW, Pessoa RM, Bezerra (2009) Giant salivary calculus of the submandibular gland. Otolaryngol Head Neck Surg 140: 1289.

3. Ledesma M C, Ortíz M G, García J S, Flores FH, Hernández-Guerrero H (2007) Giant Sialolith: Case report and review of literature. J Oral Maxillofac Surg 65 128-30.

4. Lustmann J, Regev E, Melamed YSialolithiasi s (1990) A survey on 245 patients and a review of the literature. Int J Oral Maxillofac Surg 19: 135-8.

5. Zakaria MA (1981) Giant calculi of the submandibular salivary gland. Br J Oral Surg 19: 230-232.

6. Marchal F, Kurt AM, Dulgerov P, Lehmann W (2001) Retrograde theory in sialolithiasis formation. Arch Otolaryngol Head Neck Surg 127: 66-68.

7. Williams M (1999)Sialolithisis. Otolaryngol Clin North Am 32: 819-834

8. Van den Akker HP (1988) Diagnostic imaging in salivary gland disease. Oral Surg Oral Med Oral Pathol66: 625-637.

9. Weissman JL (1995) Imaging of the salivary glands. Semin Ultrasound CT MR.16: $546-568$.

10. Zenk J, Constantinidis J, Al-Kadah B, Iro H (2001) Transoral removal of submandibular stones. Arch Otolaryngol Head Neck Surg 127: 432-436.

11. Ottaviani F, Capacio P, Campi M, Ottaviani A (1996) Extracorporea electromagnetic shock-wave lithotripsy for salivary gland stones. Laryng 106: $761-764$. 